\title{
CYSTOSCOPIC-ASSISTED URINARY BLADDER LAVAGE IN MALE CATS WITH RECURRENT URETHRAL OBSTRUCTIONS: TREATMENT AND OUICOME IN 10 CASES
}

\author{
ANDREA COCCl, Clinica Veterinaria San Siro, Milano, Italy Corresponding author: andreacocci@gmail.com \\ SIMONE MONTI, Clinica Veterinaria Valdostana, Aosta, Italy \\ VALENTINA GRECI, Ospedale Veterinario Gregorio VII, Roma, Italy
}

INTRODUCTION: Urethral obstruction (UO) is a common and potentially life threatening complication in male cats with feline lower urinary tract disease (FLUTD). Consensus regarding the most effective medical treatment to prevent recurrence of $\mathrm{UO}$ is lacking. Recurrence of UO can lead to repeated hospitalization, increase risks of urethral injury secondary to catheterization or need for surgical intervention (perineal urethrostomy, PU).

AIM OF THE WORK: to report the use of cystoscopic-assisted urinary bladder lavage and the outcome in 10 male cats with recurrent UO.

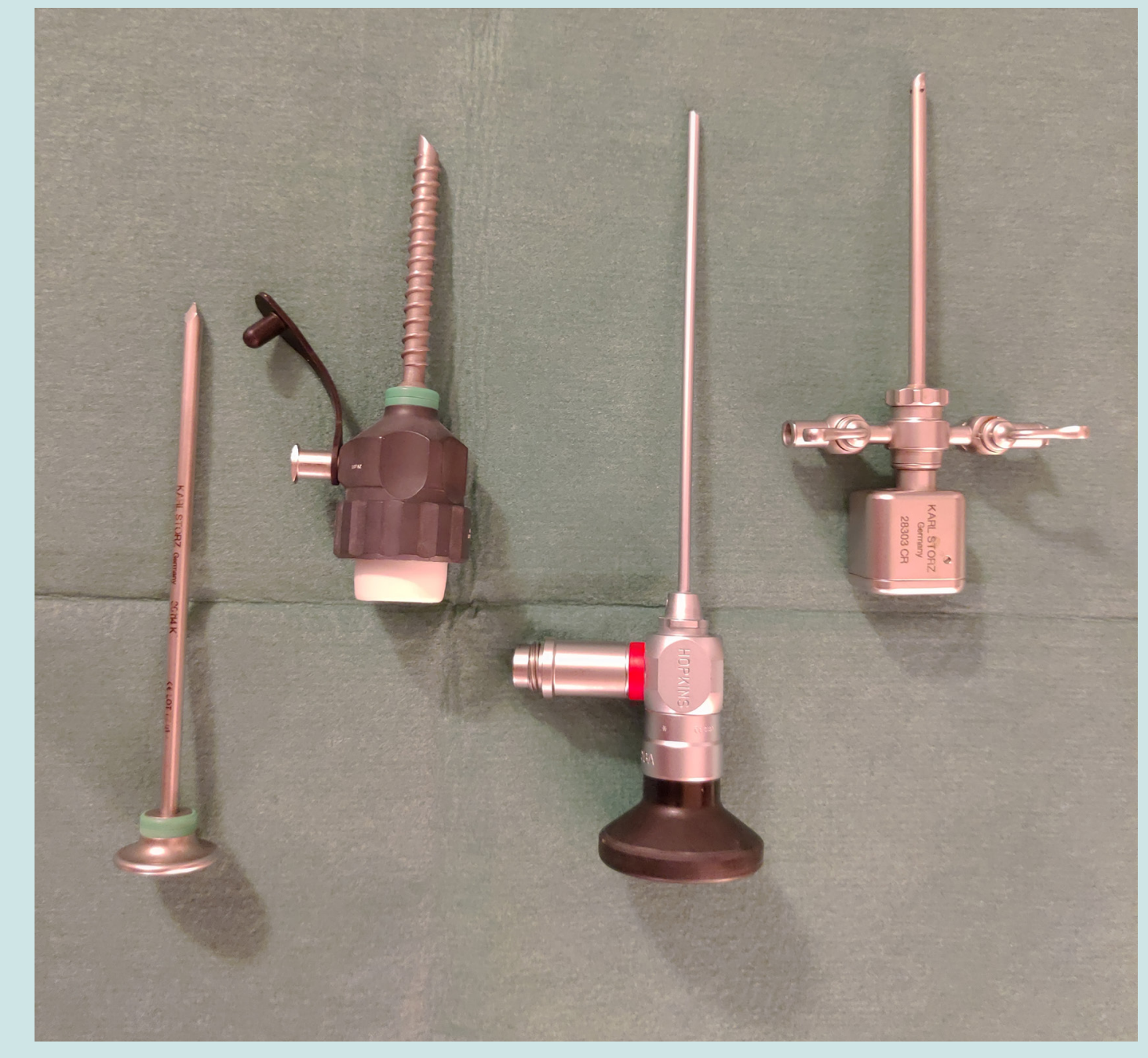

FIG. 12,4 mm rigid endoscope with 30-degree viewing angle and $4 \mathrm{~mm}$ cannulae with one and two fluid connection ports

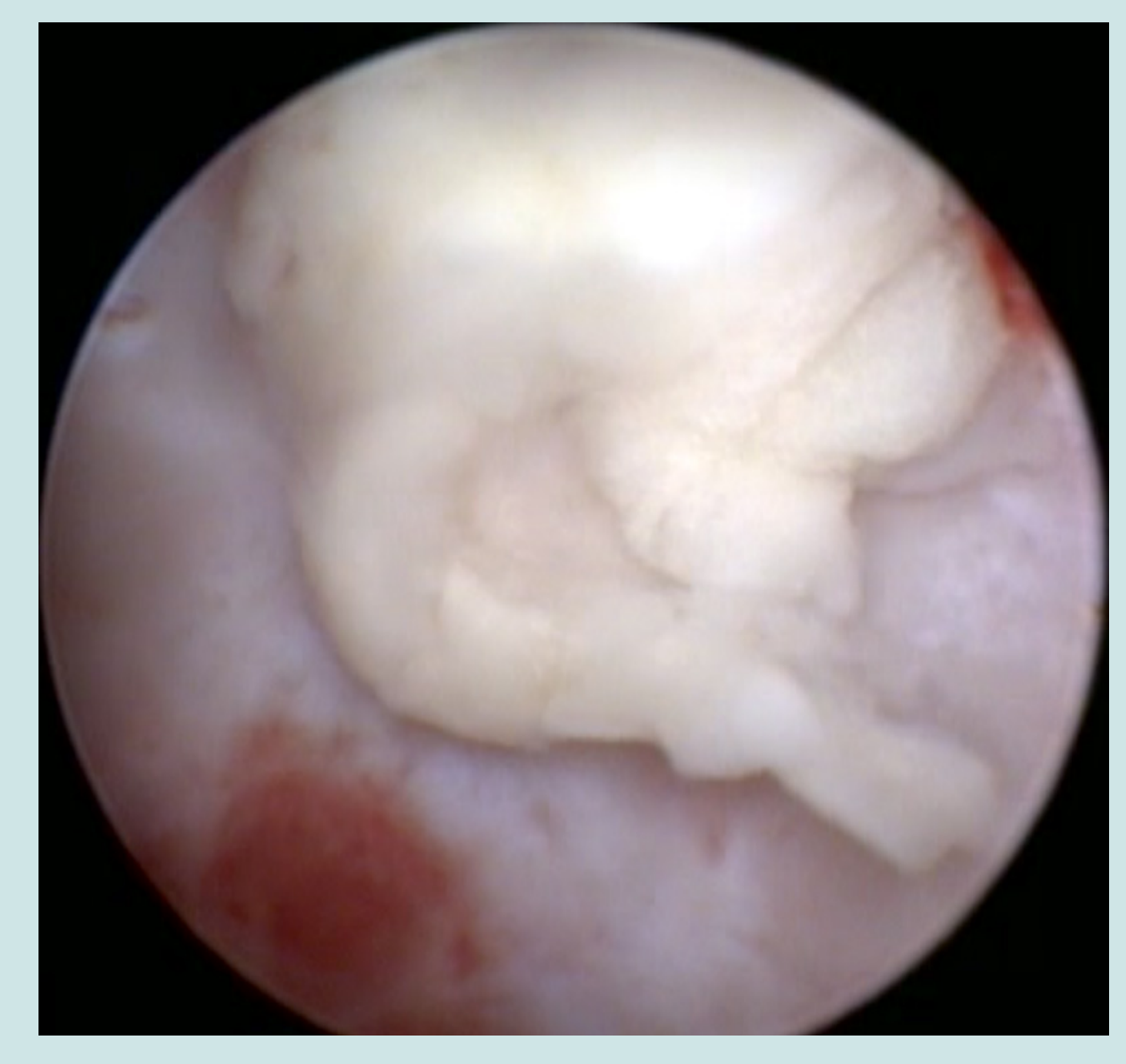

FIG. 2 Amorphous debris containing struvite in the bladde of a male cat with chronic cystitis.
MATERIALS AND METHODS: exclusion criteria were age less than 12 months, less than 2 episodes of UO, presence of any underlying disease different from FLUTD or existing PU. All ten cats were DSH castrated males with a mean age of 5.3 years (2-12 years). All ten cats showed recurrent pollakiuria and stranguria and $3 / 9$ cats macroscopic hematuria. Mean duration of clinical signs was 15.6 months (1-48 months).

All cats were anesthetized and the urinary bladder was distended with warm saline infused through a preoperatively placed rigid polypropylene open-ended, 3.5 F, tomcat catheter.

A mini-laparotomy incision on the midline, about half of the way between the pubis and the umbilicus, was performed to expose and secure the cranial region of the bladder to the abdominal wall. A $2.4 \mathrm{~mm}$ rigid cystoscope was placed, within its $3.5 \mathrm{~mm}$ cannula, through a small incision made into the ventral wall of the urinary bladder

FIG. 3 Struvite sand in the bladder of a male cat with chronic cystitis attached to the ingress/egress portal of the cannula. The scope was often withdrawn from its cannula to remove material trapped within the lumen.

All cats were discharged uneventfully with medical and dietary therapy depending on clinical condition, stress factors and urinalysis. Mean follow-up was 9.6 months (3-24 months).

One cat had recurrence of $U O$ and perineal urethrostomy was performed.
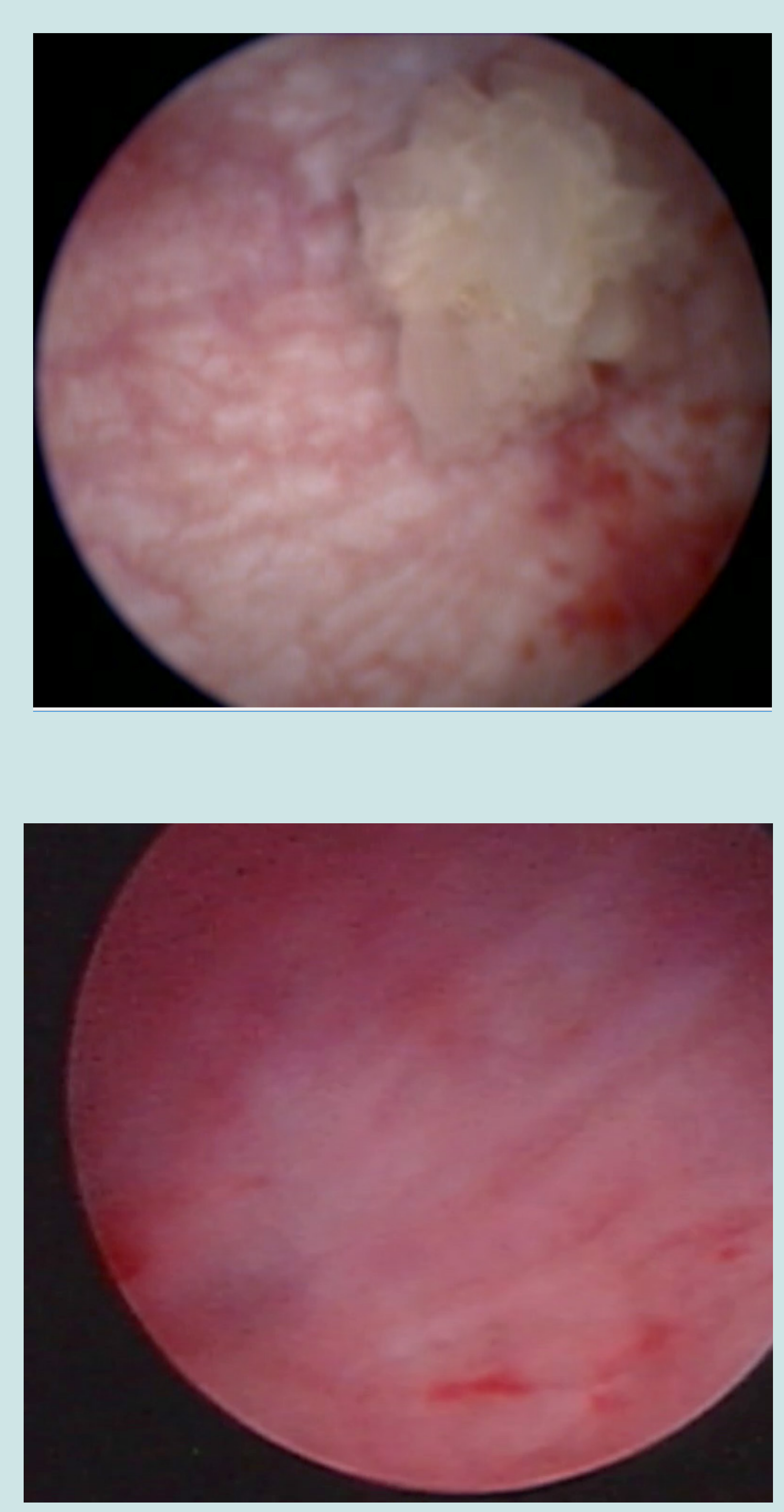

CONCLUSIONS: In this case series $9 / 10$ cats (90\%) showed long term remission of FLUTD, without recurrence of UO. Cystoscopic-assisted urinary bladder lavage might represent a more effective technique than decompressive cystocentesis or urethral catheterization in treating $U O$ in male cats. Increased endoscopic visualization and high pressure saline flow allow more accurate removal of mucous plugs, cloths and small uroliths reducing the risks for repeated catheterizations or need for PU.

\section{REFERENCES:}

Timothy C. McCarthy: Cistoscopy. In Endoscopy for the small animal practitioner 2005, Elsevier (USA)

Laparoscopic-assisted cystotomy for urolith removal in dogs and cats - 23 cases. Pinel CB, Monnet E, Reems MR.Can Vet J. 2013 Jan;54(1):36-41.

ACVIM Small Animal Consensus Recommendations on the Treatment and Prevention of Uroliths in Dogs and Cats. Lulich JP, Berent AC, Adams LG, Westropp JL, Bartges JW, Osborne CA.J Vet Intern Med. 2016 Sep;30(5):1564-1574

Controversies in the management of feline urethral obstruction. Cooper ES.J Vet Emerg Crit Care (San Antonio). 2015 Jan-Feb;25(1):130-7. 